Research Paper:

Effectiveness of Group Counseling Based On Mindfulness-

\title{
based Cognitive Therapy on Job Involvement of Employees of Islamic Azad University of Gorgan Branch
}

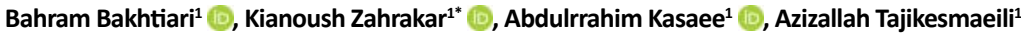

1. Department of Counseling, Faculty of Psychology and Educational Sciences, Kharazmi University, Tehran, Iran.

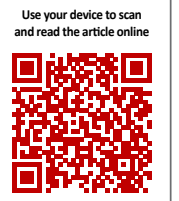

Citation Bakhtiari B, Zahrakar K, Kasaee A, Tajikesmaeili A. Effectiveness of Group Counseling Based On Mindfulness-based Cognitive Therapy on Job Involvement of Employees of Islamic Azad University of Gorgan Branch. Avicenna Journal of Neuropsychophysiology. 2018; 5(1):35-42. http://dx.doi.org/10.32598/ajnpp.5.1.35

http://dx.doi.org/10.32598/ajnpp.5.1.35

Article info:

Received: 30 Jun 2018

Accepted: 13 Oct 2018

Available Online: 01 Feb 2018

Keywords:

Mindfulness-based cognitive therapy, Group counseling, Job involvement, Employees

\begin{abstract}
A B STRACT
Background: Job involvement is an essential factor and an attitude contributing to the efficiency and effectiveness of the organization. Job involvement is based on how employees perceive their work environment, job, and its combination with personal life; its low level among the employees would reduce performance at different levels of the organization.
\end{abstract}

Objectives: The present study aimed at investigating the effectiveness of group counseling based on Mindfulness-Based Cognitive Therapy (MBCT) on the job involvement of employees in Islamic Azad University of Gorgan, Gorgan City, Iran.

Materials and Methods: The present study was quasi-experimental and used a pre-test and posttest design with a control group. The population of this research consisted of all administrative employees (other than faculty members) of the Islamic Azad University of Gorgan, Iran, in the 2017-2018 academic year. Among them, 24 individuals were randomly selected and assigned to the experimental and control groups (12 participants in each group). The Job Involvement Questionnaire (1979) was used for assessing participants' job involvement in pre-test and posttest. For the experimental group, group counseling sessions of MBCT were held in 16 sessions (each session took one hour and a half) with two sessions per week, while the control group received no intervention. The data were analyzed in SPSS V. 20, using One-Way Analysis of Covariance (ANCOVA)

Results: The results of ANCOVA showed that group counseling based on MBCT significantly increased the job involvement of the participants in the experimental group compared to the control group in their post-test $(\mathrm{F}=24.43, \mathrm{P}<0.01)$.

Conclusion: The results of this study confirmed the effectiveness of group counseling based on MBCT in increasing the employee's job involvement. It is recommended that this therapeutic approach be used in organizational and work environments for enhancing job involvement among employees and increasing organizational effectiveness.

\section{* Corresponding Author:} Kianoush Zahrakar, PhD.

Address: Department of Counseling, Faculty of Psychology and Educational Sciences, Kharazmi University, Tehran, Iran.

Tel: +98 (21) 86072738

E-mail:dr_zahrakar@khu.ac.ir 


\section{Introduction}

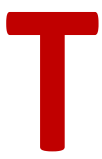

he continuity of the activities of organizations and institutions depends on how the employees work. The human being is one of the components of the work and activity, who make decisions, execute them, and predict the continuity of future activities based on them. Organizational performance is the result of the implementation processes and the realization of the organization's goals [1]. The organizational performance consists of almost all of the objectives of competitiveness and product excellence, which is related to cost, flexibility, speed, reliability, or quality. Top-quality organizations have specific characteristics in terms of prospect and organization missions, goals, strategic thinking, leadership, organization design, technology, and organizational processes [2].

If organizations have employees who are interested in their jobs and seriously engage in their jobs and duties, they will perform well. Job involvement is the way employees perceive the work environment of their job and combine it with personal life [3]. In recent years, job involvement is considered as a feedback and a career perspective by the researchers [4]. Job involvement refers to the degree to which individuals psychologically identify themselves with their current job [5]. Job involvement is defined as a passion, satisfaction, and sense of excitement in the workplace so that the employees could go beyond the tasks and objectives of the organization [6]. Among the various perspectives on job involvement, the most realistic view considers this concept as a function of personality and organizational environment [7].

In this regard, the interest in studying the concept of job involvement has focused on its determinants. With regard to these determinants, three levels of personal characteristics, situational characteristics, and work efficiency are identified [7]. Both individual variables and situational characteristics have an impact on job involvement, and the relative importance of these two sets of variables has been studied by researchers from both perspectives. Studies show that employees' involvement in the job has a significant impact on the profitability and productivity of the organization [8]. Employees, who have a favorable job involvement in their organization, understand well the organization's goals and missions, and play a key role in regulating and adjusting them [9]. Also, the results of the studies show that employees, who are more involved in their job, have reported a higher level of mental health and mental relaxation, and have shown more personal initiatives, voluntary behaviors, and learning motivation [10].
Job involvement is associated with job resources, including social support of colleagues and supervisors, performance feedback, leadership, job control, task diversity, learning and growth opportunities, and educational facilities. In addition, employees with high-level of job involvement consider their jobs more important. Low-level job involvement leads to alienation from work and organization, loss of purpose, and separation of the lives and the jobs of employees [11].

Among the new therapies in psychology used today such as Acceptance and Commitment Therapy (ACT), Mindfulness-Based Stress Reduction (MBSR), and MindfulnessBased Cognitive Therapy (MBCT) [12, 13], one of the therapeutic approaches that appears to enhance the level of job involvement in the workplace and organizations is $\mathrm{MBCT}$, which is based on the Kabat- MBSR and the principles of cognitive therapy added to it [14]. The purpose of teaching mindfulness is not to change the content of thoughts, but to create an attitude or a different relationship with thoughts, feelings, and emotions, which involves maintaining full and instantaneous attention, along with accepting and nonjudgmental attitude [15]. Mindfulness-based intervention is considered as one of the cognitive-behavioral therapies of the third-generation or third-wave [16].

The mindfulness is a kind of meditation rooted in eastern religious teachings, especially Buddhism [16].Mindfulness requires the development of three components of refraining from judgment, deliberate awareness, and concentration on the present moment in the individual's attention; it focuses on the present time and the processing of all aspects of the immediate experience, like cognitive, physiological, or behavioral activities.Through mindfulness-based exercises and techniques, people become aware of their daily activities and the automatic functioning of the mind in the past and future worlds. Through instantaneous awareness of thoughts, emotions, and physical states, the people will control them and will be released from every day and automated mind that centered on the past and the future [17].

Mindfulness awareness allows us to perceive events less distressing than they might be in the present. When we are aware of the present time, our attention is no longer involved in the past or future, while most psychological problems stem from the focus on the past [14]. The main mechanism of mindfulness seems to be the self-control of attention. By focusing on a neutral stimulus, such as breathing, it creates a proper attention environment [18]. The concept of mindfulness is at the center of this therapy program, which means paying attention to a particular method, focusing on one goal in the present moment and without any judgment. The result of developing and rais- 
ing this attention is to increase one's awareness of subjective experiences, including thoughts and feelings [19].

This therapy teaches people the skills to be aware of their thoughts without any judgments and to consider positive or neutral thoughts as the reflections of reality and transient mental events instead of negative thoughts [20]. Taheri and Sajjadian in a research entitled "the effectiveness of mindfulness-based cognitive therapy on the symptoms of fatigue, self-compassion, and mindfulness of employees with chronic fatigue syndrome" indicated a decrease in the mean scores of fatigue dimensions (mental and physical) and an increase in the mean scores of self-compassion and mindfulness in the experimental group compared to the control group [21]. In another study, Motamedi aimed at investigating the effectiveness of MBCT on job stress among employees of Iranian Fuel Conservation Company, and the findings showed that MBCT had been effective in reducing job stress among employees [22].

In another research, Askey-Jones concluded that MBCT was effective in reducing burnout and improving employees' mindfulness [23]. Job involvement is an important variable in understanding employees' behavior, boosting their performance, increasing productivity, and improving services and their quality. Thus, designing educational interventions is essential with the aim of enhancing employees' job involvement and, consequently, more productivity of the organization. Most studies on the concept of job involvement are descriptive studies, and few interventional studies are in this field. Also, the effectiveness of MBCT has been studied mainly in the clinical field and mood disorders treatments, and its effectiveness in the occupational and organizational environment has been less investigated. Regarding these issues, the present study aimed at investigating the effectiveness of group counseling based on MBCT on the job involvement of the employees in the Islamic Azad University of Gorgan, Gorgan City, Iran.

\section{Materials and Methods}

The present study was quasi-experimental and used a pretest and post-test design with the control group. The statistical population of this research consisted of all administrative employees (other than faculty members) of the Islamic Azad University of Gorgan, Iran, in the 2017-2018 academic year. The sample of this study included 24 employees, who were randomly selected and assigned to the experimental and control groups (each group included 12 people). Therefore, at the screening stage, firstly, the questionnaire of job involvement was given to all employees of the administrative department of the university (134 people).
After examining the questionnaires, in the next stage, 70 employees, who had the lowest scores in the job involvement questionnaire and had the lowest level of job involvement, were selected. At the last stage, 24 employees were randomly selected out of 70 people and randomly assigned to the experimental and control groups (12 people in each group) and were considered as the final sample. The inclusion criteria included being an administrative employee of the Islamic Azad University of Gorgan Branch in the 20172018 academic year, willing to participate in the study, and having low job involvement score. The exclusion criteria included membership in the faculty of the university and reluctance to continue the study. After assigning the participants to the groups, in the experimental group, group counseling based on MBCT was conducted in 16 sessions (each session took 90 minutes) with two sessions per week.

During the intervention therapy of the experimental group, the subjects in the control group received no intervention. The protocol of group counseling sessions based on MBCT was developed based on the book of "mindfulness therapies" compiled by Mohammad Khani and Khanipour [24]. At the end of the therapy sessions, both groups were re-evaluated by the research tool (post-test stage). To observe ethical and professional issues in the research, group counseling sessions were held for the control group after the end of the research to appreciate them for their cooperation in the implementation of the research. Table 1 presents a summary of group counseling sessions based on MBCT.

The following ethical principles were considered in the present study: 1 . The researcher introduced himself to the research units and provided explanations about the research objectives; 2.The research units were assured of keeping their personal information confidential; 3. The emphasis was placed on the freedom of the research units to continue the study or not; 4 . The personal privacy of the subjects was maintained and they were guaranteed about the safety of the interventions. Finally, the informed consent was received from all participants. The data were analyzed in SPSS V. 20, using one-way analysis of covariance.

\section{Job Involvement Questionnaire}

This questionnaire was prepared by Kanungo (1979), which consisted of 10 questions based on a 5-point Likert scale from "I totally disagree" =5, "I agree" =4, " disagree" $=3$, and "I totally disagree" $=1$, which are inversely scored in reverse questions. The minimum score is 10 , and the maximum score is $\mathbf{5 0}$. Higher scores imply a high level of job involvement [25]. Kuel et al. (2004) obtained the Cronbach' alpha of this questionnaire as (0.84) among 321 Taiwanese government employees 
Table 1. Summary of the content of group counseling sessions based on mindfulness-based cognitive therapy

\begin{tabular}{|c|c|}
\hline Session & Description of the Sessions \\
\hline 1 & $\begin{array}{l}\text { Shaping the group, introducing the principles and rules of the course and the boundaries of the group, partici- } \\
\text { pants' introducing to each other, and discussing what persuaded them to participate in the group and what they } \\
\text { want from the group }\end{array}$ \\
\hline 2 & Acquaintance with the topic of job involvement and discussing the experiences of the members \\
\hline 3 & Acquaintance with the concepts related to mindfulness and teaching attention and awareness in the workplace \\
\hline 4 & $\begin{array}{l}\text { Continuing to teach attention to and awareness of thoughts and feelings in the metacognitive method with an } \\
\text { emphasis on the transient nature of negative feeling, training meditation, physical examination, exercises and } \\
\text { giving assignments }\end{array}$ \\
\hline 5 & $\begin{array}{l}\text { Continuing to teach with an emphasis on the relationship between thoughts and feelings, focusing on thoughts } \\
\text { related to the role of occupation, meditation, physical examination, and the submission of assignments }\end{array}$ \\
\hline 6 & $\begin{array}{l}\text { Understanding the wandering mind, reviewing negative thoughts, meditation, physical examination, and review- } \\
\text { ing assignments }\end{array}$ \\
\hline 7 & $\begin{array}{l}\text { Teaching to control the wandering minds according to negative automatic thoughts, meditation, physical exami- } \\
\text { nation, and reviewing assignments }\end{array}$ \\
\hline 8 & $\begin{array}{l}\text { Teaching to find what is unpleasant in job experience, defining the scope of occupational stress or another area } \\
\text { that the group is involved in, such as chronic fatigue, feeling unmotivated, stress, etc. in the work environment } \\
\text { and doing meditation }\end{array}$ \\
\hline 9 & Teaching visual and audible mindfulness in job activity, and meditation \\
\hline 10 & $\begin{array}{l}\text { Teaching a coping strategy to use when facing a tough feeling in the current situation, walking with awareness, } \\
\text { and sitting meditation }\end{array}$ \\
\hline 11 & $\begin{array}{l}\text { A different connection allows the members to be present and experience exactly as it is without being judged, } \\
\text { trying to change what is in the organization, and doing meditation }\end{array}$ \\
\hline 12 & $\begin{array}{c}\text { Practicing emotions, thoughts, and alternative views identifying the signs of relapses that may vary from person } \\
\text { to person and doing meditation }\end{array}$ \\
\hline 13 & $\begin{array}{l}\text { Teaching a practical program for dealing with negative emotions, thoughts, and feelings in job activity, and doing } \\
\text { meditation }\end{array}$ \\
\hline 14 & $\begin{array}{c}\text { Understanding the relationship between work and emotions, preparing a list of daily activities and determining } \\
\text { which one is repulsive, which one is inspiring, and which one creates a sense of consolation or pleasure in the } \\
\text { person, identifying the relapse symptoms and developing activities to deal with the threat of relapse and doing } \\
\text { meditation }\end{array}$ \\
\hline 15 & $\begin{array}{l}\text { An overview of early warning systems and action plans that are available for use when the risk of relapse is high } \\
\text { and teaching skills in this area, doing meditation and preparing participants for ending the course }\end{array}$ \\
\hline 16 & $\begin{array}{c}\text { An overview of what is learned during the course, and what is most valuable to you in your life, especially in your } \\
\text { job that doing these exercises could help you reach them }\end{array}$ \\
\hline
\end{tabular}

AJNPP

[26]. In the research of Motalebi and Kiani, the Cronbach' alpha of this questionnaire was estimated as 0.83 for 116 teachers of special schools [27]. In the present study, the Cronbach' alpha of this questionnaire was (0.78).

\section{Results}

Nine males and 3 females were present in the experimental group (MBCT), and 8 males and 4 females were present in the control group. Table 2 shows the demographic information of the two groups; based on the information in Table 2, the participants aged 36 to 40 years are the most frequent group in both groups. Also, according to the information contained in Table 2, 5 individuals had an undergraduate degree, and seven had graduated degree in the experimental group (MBCT); moreover, 4 individuals had an undergraduate degree, and 8 had graduated degrees in the control group.

Table 3 shows the mean and standard deviation of the job involvement in the pre-test and post-test stages of the experimental and control groups. According to the data of Table 3, the mean job involvement scores in the experimental group (MBCT) was (29.75) in the pre-test, which was changed to (32.92) in the post-test. In the control group, the mean scores of this variable were (28.58) in the pre-test and (29.25) in the post-test. As seen in the Table 3, the scores of the job involvement of the experimental group had some changes in the posttest stage. One-way Analysis of Covariance (ANCOVA) was used to determine that these changes of the variable the in post-test of the research were statistically 
Table 2. Demographic information of participants by groups

\begin{tabular}{|c|c|c|c|c|}
\hline \multirow{2}{*}{\multicolumn{2}{|c|}{ Variable }} & \multicolumn{2}{|c|}{ No. \% } & \multirow{2}{*}{$\mathbf{P}$} \\
\hline & & Experimental Group & Control Group & \\
\hline \multirow{5}{*}{ Age, $y$} & $30-35$ & $2(16.7)$ & $1(8.3)$ & \multirow{5}{*}{$>0.675$} \\
\hline & $36-40$ & $6(50)$ & $6(50)$ & \\
\hline & $41-45$ & $2(16.7)$ & $3(25)$ & \\
\hline & $46-50$ & $2(16.7)$ & $2(16.7)$ & \\
\hline & Total & $12(100)$ & $12(100)$ & \\
\hline \multirow{3}{*}{ Educational level } & Undergraduate & $5(41.7)$ & $4(33.3)$ & \multirow{3}{*}{0.712} \\
\hline & Graduated & $7(58.3)$ & $8(66.7)$ & \\
\hline & Total & $12(100)$ & $12(100)$ & \\
\hline
\end{tabular}

Table 3. Mean $\pm S D$ of job involvement in pre-test and post-test

\begin{tabular}{cccc}
\hline \multirow{2}{*}{ Variable } & Stage & Mean \pm SD & \\
\cline { 3 - 4 } & & Experimental Group & Control Group \\
\hline \multirow{2}{*}{ Job Involvement } & Post-test & $29.75 \pm 3.10$ & $28.58 \pm 2.74$ \\
& & $35.92 \pm 2.46$ & $29.25 \pm 3.64$
\end{tabular}

AJNPP

significant. The use of this test requires observing a few important assumptions, including the normal distribution of scores, the homogeneity of variances, and the homogeneity of the regression lines slope. Therefore, these assumptions are first examined.

The Kolmogorov-Smirnov test was used to check the normal assumption. Since the test values for the job involvement were not significant in any of the experimental and control groups ( $P>0.05)$, the distribution of scores in this variable was normal. Also, Levene's test was used to examine the homogeneity of variance. There was no significant difference between the vari- ances of the experimental and control groups according to $F$ value $(F=0.057, P>0.05)$. According to this assumption, the homogeneity of the experimental and control groups was confirmed. Finally, the assumption of the homogeneity of regression slope was met.

Considering that the assumptions of using the analysis of covariance are met, the results are presented in the following Table 4. As shown in Table 4, the results of ANCOVA showed a significant difference between the job involvement of the experimental groups (MBCT) and the control group $\left(\mathrm{F}={ }_{24.43}, \mathrm{P}=0.001\right)$. According to the mean values of this variable's post-test in the ex-

Table 4. Results of covariance analysis of the effect of therapy on job involvement scores

\begin{tabular}{ccccccc}
\hline Sources of Change & Sum of Squares & df & Mean Square & F & P & Effect Size \\
\hline Pre-test & 13.75 & 1 & 13.75 & 1.44 & 0.242 & - \\
Group & 232.07 & 1 & 232.07 & 24.43 & 0.001 & 0.53 \\
Error & 199.41 & 21 & 9.49 & - & - & - \\
Total & 25960 & 24 & - & - & - & - \\
\hline
\end{tabular}


perimental group (MBCT) (35.92) and the control group (25.29), the therapy increased the mean scores of the experimental group's post-test. Based on the effect size in the Table 4, the effect size of this therapy was (53\%). Therefore, based on the study results, group counseling based on MBCT has been effective in the increasing job involvement of employees in the Islamic Azad University of Gorgan, Iran.

\section{Discussion}

The purpose of this study was to investigate the effectiveness of group counseling on the job involvement of employees in the Islamic Azad University of Gorgan. The results of the effectiveness of group counseling based on $\mathrm{MBCT}$ in promoting employees' job involvement were confirmed. Studies that were directly related to the findings of this research were not found, but the findings of this study were in line with the results of the studies by Askey-Jones, Slutsky et al. Suyi et al. Hansen, Hülsheger, Alberts, Feinholdt and Lang, Wongtongkam et al. Zahedi Rad et al. Taheri and Sajjadian, Rastgoo et al. Motamedi, and Haghi et al. [21-23, 28-33].

These studies approved the effectiveness of MBCT on improving the occupational and organizational structure. In explaining the results of this research, it is worth mentioning that the basic hypothesis of MBCT states that the mind has two types of modes; doing mode and being mode, through which it can process the experience. The main goal of MBCT is to inform the patients about the effects of the reactivation of doing mode through automatic pilot, to stay in being mode by using and creating the mindfulness state, and to observe their thoughts and feelings through repeated exercises that focus on a neutral object (e.g. breathing, body sensation) [34].

Mindfulness is a non-judgmental and unexplainable consciousness and based on present-day experience, which happens at a particular moment within the scope of the individual's attention. Moreover, this concept is defined as confessing to experience and also includes its acceptance. Increasing mindfulness is effective in increasing the social and psychological wellbeing in terms of acceptance, perceptiveness, and personal development; it allows the individual to respond to the events by thinking and reflection instead of responding involuntarily and without thinking and helps them to identify, manage, and solve the everyday problems [35].

The purpose of using meditation techniques in this therapy is to help individuals to become more aware of their experiences at the moment and to realize when their emotions begin to decline so that the connection between negative emotions and negative thoughts would be destroyed and they would learn how to take care of themselves when their emotions are declined. The focus of teaching $\mathrm{MBCT}$ is on informing people about thoughts and feelings and considering them as mental events rather than aspects of self-reflection or reflection of reality [36]. MBCT focuses on modifying, controlling, and processing thoughts. The first and foremost factor in the development of MBCT is the fundamental mindfulness.

It is based on the acceptance of unpleasant thoughts, and different emotional states greatly enhances the individual's ability to control the influence of his thoughts and his emotions and allows the individual to have a wide range of thoughts and emotions without experiencing emotional distress in mind. Also, fundamental mindfulness, which has a great ability of reducing anxiety and stress and increasing the individuals' attention, helps individuals maintain their emotional stability in facing with self-conscious thoughts that would turn into ruminating because of its emotional load, and not paying too much attention to the disturbances, but watching the thoughts passes their mind. This ability makes self-conscious thoughts not to create more mind engagements than previously created for the individual and not to become ruminant. Also, focusing and attention practice on breathing as a means of living in the present should be used [37].

Every research has some limitations. Considering that this study was carried out on employees of the Islamic Azad University of Gorgan, it is necessary to take caution in generalizing its results to other employees and universities. Selfreporting tools are other limitations of the research, which should be considered. The absence of a follow-up phase and, consequently, the lack of information about the continuity of the change or the stability of the results is another limitation of the research. Another limitation is the lack of control of the underlying and individual factors.

The participants likely overestimated the effect of the program because of some underlying factors. Another possible assumption is that individuals have overestimated the effect of the program because of personal tendencies, optimism, and similar factors. Based on the findings of the present study, it is recommended that job counselors use the components of an MBCT model to decrease job problems and increase the effectiveness of organizations. 


\section{Conclusions}

The results of this study confirmed the effectiveness of group counseling based on MBCT on increasing the employee's job involvement. It is recommended that this therapeutic approach be used in organizational and work environments for enhancing job involvement among employees and increasing organizational effectiveness.

\section{Ethical Considerations}

\section{Compliance with ethical guidelines}

The researcher introduced himself to the research units and provided explanations about the research objectives. The research units were assured to keep personal information confidential. The emphasis was placed on the freedom of the research units to continue the study or not. The personal privacy of the subjects was maintained, and they were guaranteed about the safety of the interventions. Finally, informed consent was received from all participants.

\section{Funding}

This article is based on the PhD dissertation of the first author at Kharazmi University in Tehran, Iran, which was approved by the Faculty of Psychology and Educational Sciences.

\section{Authors' contributions}

All authors equally contributed in preparing this article.

\section{Conflict of interest}

The authors declared no conflict of interest.

\section{Acknowledgments}

The research group would like to thank all of the employees of the Islamic Azad University of Gorgan, who helped the researchers in this study with their sincere cooperation.

\section{References}

[1] Sokro E. Analysis of the relationship that exists between organisational culture, motivation and performance. Problems of Management in the $21^{\text {st }}$ Century. 2012; 3(3):106-99.
[2] Chiang YH, Shih HA, Hsu CC. High commitment work system, transactive memory system, and new product performance. Journal of Business Research. 2014; 67(4):631-40. [DOI:10.1016/j.jbusres.2013.01.022

[3] Hirschfeld RR. Achievement orientation and psychological involvement in job tasks: The interactive effects of work alienation and intrinsic job satisfaction. Journal of Applied Social Psychology. 2002 32(8):1663-81. [DOI:10.1111/j.1559-1816.2002.tb02768.x]

[4] Kopperud KH, Martinsen $\varnothing$, Humborstad SIW. Engaging leaders in the eyes of the beholder: On the relationship between transformational leadership, work engagement, service climate, and self-othe agreement. Journal of Leadership \& Organizational Studies. 2014; 21(1):29-42. [DOI:10.1177/1548051813475666]

[5] Deepak. Antecedent value of professional commitment and job involvement in determining job satisfaction. Management and Labour Studies. 2016; 41(2):154-64. [DOI:10.1177/0258042X16658732]

[6] Lambert EG, Paoline EA. Exploring potential antecedents of job involvement: An exploratory study among jail staff. Criminal Justice and Behavior. 2012; 39(3):264-86. [DOI:10.1177/0093854811433533]

[7] Elankumaran S. Personality, organizational climate and job in volvement: An empirical study. Journal of Human Values. 2004 10(2):117-30. [DOI:10.1177/097168580401000205]

[8] Harter JK, Schmidt FL, Hayes TL. Business-unit-level relationship between employee satisfaction, employee engagement, and business outcomes: A meta-analysis. Journal of Applied Psychology. 2002 87(2):268-79. [DOI:10.1037/0021-9010.87.2.268] [PMID]

[9] Litten JP, Vaughan AG, Wildermuth CD. The fabric of engagement: The engagement and personality of managers and professionals in human and developmental disability services. Journal of Social Work in Disability \& Rehabilitation. 2011; 10(3):189-210. [DOI:10.1 080/1536710X.2011.596447] [PMID]

[10] Bakker AB, Demerouti $E$. The crossover of work engagement between working couples: A closer look the role of empathy. Journal of Managerial Psychology. 2009; 24(3):220-36. [DOI:10.1108/02683940910939313]

[11] Schaufeli W, Taris T, Van Rhenen W. Workaholism, burnout and work engagement: Three of a kind or three different kinds of employee well-being? Applied Psychology. 2008; 57(2):173-203. [DOI:10.1111/j.1464-0597.2007.00285.x]

[12] Hajsadeghi Z, Yazdi-Ravandi S, Pirnia B. Compassion-focused therapy on levels of anxiety and depression among women with breast cancer: A randomized pilot trial. International Journal of Cancer Management. 2018; 11(11):e67019. [DOI:10.5812/ijcm.67019]

[13] Azami E, Hajsadeghi Z, Yazdi-Ravandi S. [The comparative study of effectiveness of training communication andemotional skills on parenting stress of mothers with autism children (Persian)]. Zanko Journal of Medical Sciences 2017; 18(56):1-11.

[14] Kabat-Zinn J. Mindfulness-based interventions in context: past present, and future. Clinical Psychology. 2003; 10(2):144-56. [DOI:10.1093/clipsy/bpg016]

[15] MacKenzie M, Kocovski N. Mindfulness-based cognitive therapy for depression: Trends and developments. Psychology Research and Behavior Management. 2016; 9:125-32. [DOI:10.2147/PRBM. S63949] [PMID] [PMCID]

[16] Tollstedt A. Mindfulness-based cognitive therapy: The experience of practice over time. London: University College London; 2017. 
[17] Segal Z, Williams J, Teasdale J. Mindfulness-based cognitive therapy for depression. New York: The Guilford Press; 2012.

[18] Semple R, Burke C. State of the research: Physical and mental health benefits of mindfulness-based interventions for children and adolescents. OBM Integrative and Complementary Medicine. 2019; 4(1):31. [DOI:10.21926/obm.icm.1901001]

[19] Parsons C, Crane C, Parsons L, Fjorback L, Kuyken W. Home practice in mindfulness-based cognitive therapy and mindfulness-based stress reduction: A systematic review and meta-analysis of participants' mindfulness practice and its association with outcomes. Behaviour Research and Therapy. 2017; 95:29-41. [DOI:10.1016/j. brat.2017.05.004] [PMID] [PMCID]

[20] Crane R. Mindfulness-based cognitive therapy: Distinctive features. Abingdon: Routledge; 2017. [DOI:10.4324/9781315627229]

[21] Taheri S, Sajjadian E. [The effectiveness of mindfulness-based cognitive therapy on fatigue symptoms, self-compassion and mindfulness of employees with chronic fatigue syndrome (Persian)]. Occupational and Organizational Counseling Quarterly Journal. 2017; 9(30):145-71.

[22] Motamedi F. The effectiveness of mindfulness-based cognitive therapy on job stress among employees of Fuel Conservation Company. Azad Shahr: Islamic Azad University; 2015.

[23] Askey-Jones R. Mindfulness-based cognitive therapy: An efficacy study for mental health care staff. Journal of Psychiatric and Mental Health Nursing. 2018; 25(7):380-9. [DOI:10.1111/jpm.12472] [PMID]

[24] Mohammad Khani P, Khanipour H. Mindfulness-based therapies (along with a practical guide for mindfulness-based cognitive therapy to prevent depression relapse). Tehran: Publications of University of Welfare and Rehabilitation Sciences; 2017.

[25] Kanungo RN. The concepts of alienation and involvement revisited. Psychological Bulletin. 1979; 86(1):119-38. [DOI:10.1037/00332909.86.1.119]

[26] Kuel S, Jaw B, Wang C, Chen J. The effect of government empirical study of Taiwan province government reengineering. Journal of $\mathrm{Hu}-$ man Resource Management. 2004; 41(1):1-28.

[27] Motallebi K, Kiani Q. The Correlation between Job burnout and mental health of teachers in special schools of Zanjan: Mediation of job involvement. Journal of Health Promotion Management. 2017 6(3):52-60. [DOI:10.21859/jhpm-07017]

[28] Slutsky J, Chin B, Raye J, Creswell JD. Mindfulness training improves employee well-being: A randomized controlled trial Journal of Occupational Health Psychology. 2019; 24(1):139-49. [DOI:10.1037/ocp0000132] [PMID]

[29] Suyi $Y$, Meredith P, Khan A. Effectiveness of mindfulness intervention in reducing stress and burnout for mental health professionals in Singapore. Explore. 2017; 13(5):319-26. [DOI:10.1016/j. explore.2017.06.001] [PMID]

[30] Wongtongkam N, Krivokapic-Skoko B, Duncan R, Bellio M. The influence of a mindfulness-based intervention on job satisfaction and work-related stress and anxiety. International Journal of Mental Health Promotion. 2017; 19(3):134-43. [DOI:10.1080/14623730.20 17.1316760]

[31] Zahedi Rad Z, ShafiAbadi A, Zare Bahram Abadi M. The Use of Mindfulness-based Cognitive Therapy for Improving Flow Experience of Nurses in the Psychiatric Hospitals. European Psychiatry 2015; 30(Suppl. 1):1037. [DOI:10.1016/S0924-9338(15)30815-4]
[32] Rastgoo N, Herfedost M, Kheyrjoo E. [The effectiveness of a group-based mindfulness training on teacher's burnout, job satisfaction, and some psychopathological symptoms (Persian)]. Journal of Cognitive Strategies in Learning. 2017; 4(7):179-98.

[33] Haghi A, Salimi S, Dabaghi P, Rabiei M. [The effectiveness of mindfullness based cognitive therapy on quality of life in military personnel (Persian)]. Journal of Nurse and Physician Within War. 2015; 2(3):64-71.

[34] Didonna F. Clinical handbook of mindfulness. New York: Springer 2009. [DOI:10.1007/978-0-387-09593-6]

[35] Emanuel AS, Updegraff JA, Kalmbach DA, Ciesla JA. The role of mindfulness facets in affective forecasting. Personality and Individual Differences. 2010; 49(7):815-8. [DOI:10.1016/j.paid.2010.06.012]

[36] Hollis-Walker L, Colosimo K. Mindfulness, self-compassion, and happiness in non-meditators: A theoretical and empirical examination. Personality and Individual Differences. 2011; 50(2):222-7. [DOI:10.1016/j.paid.2010.09.033]

[37] Teasdale JD, Segal ZV, Williams JMG, Ridgeway VA, Soulsby JM, Lau MA. Prevention of relapse/recurrence in major depression by mindfulness-based cognitive therapy. Journal of Consulting and Clinical Psychology. 2000; 68(4):615. [DOI:10.1037/0022006X.68.4.615] [PMID] 